\title{
Association of Helicobacter pylori Infection with Vitamin D Deficiency in Infants and Toddlers
}

\author{
Ting Gao, ${ }^{1,2} \dagger$ Mengwen Zhao, ${ }^{1} \dagger$ Chen Zhang, ${ }^{1}$ Peipei Wang, ${ }^{1}$ Wenjuan Zhou, ${ }^{1}$ Shan Tan, ${ }^{1}$ and Lingling Zhao ${ }^{1 *}$ \\ ${ }^{1}$ Department of Pediatrics, Central South University Third Xiangya Hospital, Changsha, China; ${ }^{2}$ Department of Neurology, The Affiliated \\ Children's Hospital of Xi'an Jiaotong University, Xi'an Shaanxi, China
}

\begin{abstract}
Helicobacter pylori (H. pylori), a gram-negative pathogen, has been shown to colonize multiple organs and cause various forms of extra-gastrointestinal diseases. The association of $H$. pylori infection with vitamin $D$ status in apparently healthy children remained unclear; therefore, we investigated the relationship between vitamin $\mathrm{D}$ and $H$. pylori infection among apparently healthy infants and toddlers. In this large cross-sectional study, the examination data of children were collected from January 2013 to September 2017 in the Center for Children's Health Care. Among these children, 6,896 infants and toddlers were screened for our study. Helicobacter pylori infection and vitamin D status were the main indicators, and micronutrients (zinc, iron, copper, magnesium), and growth parameters (height, weight, and weight for age $Z$ score [WAZ], height for age $Z$ score [HAZ]) were also analyzed in this study. Among the 6,896 infants and toddlers, the detection rate of $H$. pylori seropositivity was $30.6 \%$. The prevalence of vitamin $\mathrm{D}$ deficiency in $H$. pylori seropositive and seronegative groups was $20.7 \%$ and $12.1 \%$, respectively $(P<0.001)$. The logistic regression analysis suggested children with $H$. pylori-positive antibody were 2.06 times more likely to be vitamin D deficient compared with children who had negative $H$. pylori antibody (odds ratio: $2.06 ; 95 \% \mathrm{Cl}: 1.77,2.38$ ) after controlling for confounding factors. These data suggested that there was a significant association between $H$. pylori seropositivity and vitamin $\mathrm{D}$ deficiency in children aged 6-36 months, which would make a contribution to the treatment and monitoring of vitamin D deficiency and $H$. pylori infection.
\end{abstract}

\section{INTRODUCTION}

Helicobacter pylori (H. pylori), one of the most common infectious bacteria, is known as the cause of digestive tract diseases. ${ }^{1}$ At present, more and more articles emphasize the relationship between $H$. pylori infection and extra-gastrointestinal diseases, ${ }^{2}$ such as refractory iron deficiency anemia, autoimmune thrombocytopenic purpura, asthma, urticaria, poor neurodevelopment, and growth and development retardation. ${ }^{2-7}$

A large number of studies have confirmed that $H$. pylori infection primarily happens in childhood, ${ }^{8}$ especially in the early stage of life. Most individuals carry a lifelong $H$. pylori infection if regular radical treatment is not administered. ${ }^{1}$ Unlike adult patients, children with $H$. pylori infection do not have severe digestive symptoms. ${ }^{9}$ However, mounting evidence suggests that children with $H$. pylori infection, even without gastrointestinal symptoms, may develop other diseases, ${ }^{10,11}$ of which growth retardation and micronutrient deficiencies are most concerning. ${ }^{12,13}$

Infancy and toddlerhood are the fastest growth phases for individuals. Many infants and toddlers are diagnosed with $H$. pylori infection only after healthy physical examination for lack of significant clinical symptoms. 1, 25-dihydroxyvitamin D3 $\left(1,25(\mathrm{OH})_{2} \mathrm{D} 3\right)$ is critical for the health of the infants and toddlers. Studies have shown that $H$. pylori infection affects the level of vitamin $D$ receptor both at the tissue and the cell levels. In the previous research, there was preliminary work on the relationship between $H$. pylori infection and vitamin $D$ deficiency, which explained that clinical research of 496 H. pylori-positive and $257 \mathrm{H}$. pylori-negative adults demonstrated serum vitamin $D$ levels were significantly lower in the H. pylori-infected group compared with control group. ${ }^{14}$ However, the association between vitamin D deficiency and

\footnotetext{
* Address correspondence to Lingling Zhao, Department of Pediatrics, The Third Xiangya Hospital of Central South University, 138, Tong Zipo, Changsha, China. E-mail: Ilzhao2011@qq.com
}

†These authors contributed equally to this work.
H. pylori infection in infants and toddlers remains unknown and still needs studies with larger samples.

In this large cross-sectional study, we analyzed the examination data of apparently healthy infants and toddlers, compared the status of vitamin $\mathrm{D}$ of $H$. pylori seropositive and seronegative groups, and further investigated the relationship between $H$. pylori infection and vitamin $\mathrm{D}$ deficiency.

\section{RESEARCH POPULATION AND INDICATORS}

Research population and exclusion criteria. The study population and indicators were extracted from a pre-built database, which met the following requirements: 1) The establishment of this data platform followed the code of conduct and the use of data in health research. 2) It was approved by The Institutional Review Board of Central South University (Approval No. 2018-S228). 3) Informed consents were obtained before the use and storage of clinical data. 4) The data entry and review were carried out by professionals, during which strict checks were made. The examination data were collected from January 2013 to October 2017 in Children Health and Care Center in the Third Xiangya Hospital, Central South University, Changsha, China.

In this study, we included the infants and toddlers whose age varied from 6 to 36 months and excluded the subjects without $H$. pylori serum antibody test result, with abnormal birth history such as premature birth, multiple births, and asphyxia or with severe disease history, such as genetic metabolic disease, congenital dysplasia, feeding difficulties, severe malnutrition, repeated respiratory diseases, and severe liver and kidney dysfunction.

The physical examination data of 100,333 children were collected from January 2013 to September 2017 , and 16,289 cases were at age varying from 6 to 36 months. Of 16,289 cases, 9,393 were excluded (7,597 were not screened for $H$. pylori serum antibody, 1,021 were abnormally born, and 775 were severely ill). In our study, 6,896 apparently healthy infants and toddlers were selected including 2,113 
H. pylori-seropositive cases and 4,783 $H$. pylori-seronegative cases. The schematic of the subject selection was shown in Figure 1.

Research indicators. In this study, demographic characteristics (age, gender, and place of residence), $H$. pylori infection status, micronutrients (zinc, iron, copper, magnesium, and vitamin D), and physical development indicators (height, weight, and weight-for-age $Z$ score [WAZ] and height-for-age $Z$ score [HAZ]) of all study population were extracted. We defined the children with all of these data as those with complete healthy physical examination data. Helicobacter pylori infection and vitamin $\mathrm{D}$ deficiency were the main indicators.

Helicobacter pylori infection was detected by the colloidal gold method for anti-H. pylori lgG (the kit was prepared by Singapore MP biomedical company, The Cavendish, Singapore), according to the manufacturer's instructions. The status of 25 hydroxyvitamin D (25-OH-D) was detected by ELISA (the kit was produced by Aomeng company, Lubeck, Schleswig-Holstein, Germany). $25-\mathrm{OH}-\mathrm{D}$ level $\geq 20 \mathrm{ng} / \mathrm{mL}$ was designated as vitamin D sufficiency and 25-OH-D level $<20 \mathrm{ng} /$ $\mathrm{mL}$ was defined as vitamin $\mathrm{D}$ deficiency. ${ }^{15}$ The atomic absorption method (the experimental instrument adopted BH7100S, Beijing Bohui, Beijing, China) was adopted to accomplish the determination of iron, zinc, copper, and magnesium.

Weight and height of children were measured. The children were laid in a supine position with the neck in a neutral position wearing light clothes and no shoes. The measurement was performed by two independent observers to make the differences less than $0.01 \mathrm{~kg}$ and $0.5 \mathrm{~cm}$, respectively. For eliminating confounding effects of age and gender, WAZ and HAZ were used to conduct statistical analysis and were calculated by WHO Anthro Software (version 3.2.2, 2011).

\section{STATISTICAL ANALYSIS}

We used a chart review to perform descriptive statistics, with categorical variables summarized as frequencies and proportions and continuous variables as median and range.
The rank-sum test was used for continuous variables between the $H$. pylori-seropositive group and $H$. pylori-seronegative group, and chi-square test was applied for categorical variables. The logistic regression analysis was used to explore the relationship between $H$. pylori infection and vitamin $D$ deficiency in apparently healthy infants and toddlers, and the odds ratio (OR) and $95 \% \mathrm{Cl}$ were calculated. $P<0.05$ was considered statistically significant. Statistical Package for the Social Sciences was used in this study (SPSS for Windows 21.0, IBM Corp., Armonk, NY).

\section{RESULTS}

Baseline characteristics of the subjects. The characteristics of the subjects at baseline are shown in Table 1. Among the 6,896 cases, the detection rate of $H$. pylori seropositivity was $30.6 \%(2113 / 6,896)$. The medians of $25-\mathrm{OH}-\mathrm{D}$ in the $H$. pylori-seropositive group and the $H$. pylori-seronegative group were $26.3 \mathrm{ng} / \mathrm{mL}$ and $26.7 \mathrm{ng} / \mathrm{mL}$, respectively. A significant difference was observed in the 25-OH-D level between $H$. pylori-seropositive and $H$. pylori-seronegative groups $(P<0.001)$. The prevalence rates of $H$. pylori seropositivity in urban and rural subjects were $29.6 \%(1,625 / 5,481)$ and $34.5 \%(488 / 1,415)$, respectively $(P<0.001)$. There were also significant differences in the age and levels of hemoglobin, copper, iron, and magnesium between $H$. pylori-seropositive and $H$. pylori-seronegative groups; however, no significant difference was detected in the gender, level of zinc, weight, and height between those two groups.

What is more in our study is that growth parameters such as WAZ and HAZ were analyzed for eliminating confounding effects of age and gender. And results showed that HAZ was relatively lower in $H$. pylori seropositivity group. However, there was no statistical difference in WAZ between $H$. pyloriseropositive and the $H$. pylori-seronegative groups as presented in Table 1.

Factors associated with vitamin D deficiency. In Table 2, it was obvious that among 6,896 apparently healthy infants

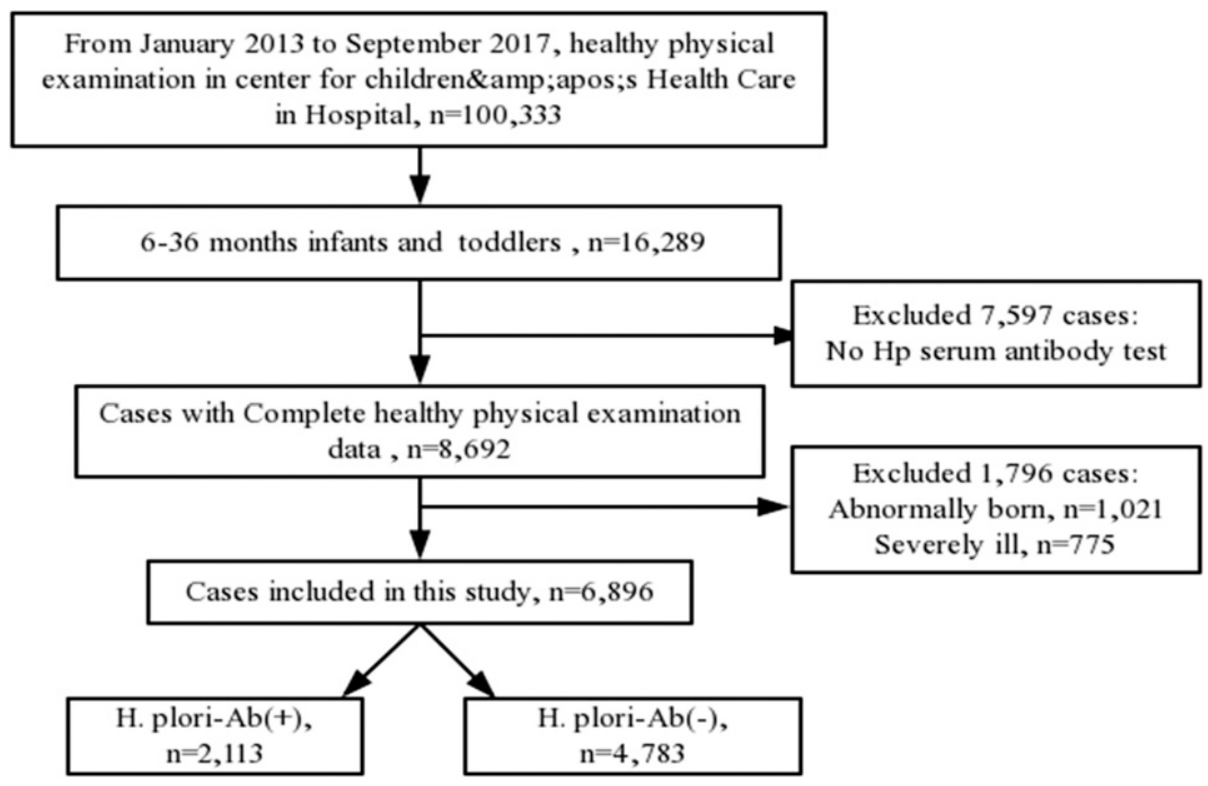

FigurE 1. Schematic of the subject selection in the study. 
HELICOBACTER PYLORI INFECTION WITH VITAMIN D DEFICIENCY

TABLE 1

Characteristics of subjects at baseline $(\mathrm{n}[\%]) /(\mathrm{M}[\mathrm{P} 25, \mathrm{P} 75])$

\begin{tabular}{|c|c|c|c|c|}
\hline \multirow[b]{2}{*}{ Independent variable } & \multicolumn{2}{|c|}{ Groups } & \multirow[b]{2}{*}{$x^{2} / Z$} & \multirow[b]{2}{*}{$P$} \\
\hline & H. pylori-Ab(+), $n=2113(30.6 \%)$ & H. pylori-Ab(-), $n=4,783(69.4 \%)$ & & \\
\hline Age (months, M) (P25, P75) & $12.1(7.2,18.4)$ & $12.4(7.0,19.7)$ & -2.48 & 0.01 \\
\hline Gender, $n(\%)$ & & & 0.34 & 0.59 \\
\hline Male & $1,202(30.9)$ & 2685 (69.1) & - & - \\
\hline Female & $911(30.3)$ & $2098(69.7)$ & - & - \\
\hline Hemoglobin (g/L, M) (P25, P75) & $118(112,124)$ & $117(110,122)$ & -2.18 & 0.03 \\
\hline $25-\mathrm{OH}-\mathrm{D}(\mathrm{ng} / \mathrm{mL}, \mathrm{M})(\mathrm{P} 25, \mathrm{P} 75)$ & $26.3(21.1,28.2)$ & $26.7(22.5,28.6)$ & -3.84 & $<0.001$ \\
\hline Copper ( $\mu \mathrm{mol} / \mathrm{L})$ & $13.3(12.4,14.0)$ & $13.2(12.3,13.9)$ & - & $<0.001$ \\
\hline Zinc $(\mu \mathrm{mol} / \mathrm{L})$ & $56.4(50.3,62.10)$ & $56.1(50.5,61.6)$ & - & 0.18 \\
\hline Iron $(\mu \mathrm{mol} / \mathrm{L})$ & $7.3(6.8,7.8)$ & $7.2(6.7,7.8)$ & - & 0.02 \\
\hline Magnesium ( $\mu \mathrm{mol} / \mathrm{L})$ & $1.5(1.3,1.6)$ & $1.4(1.3,1.5)$ & - & $<0.001$ \\
\hline Weight (kg, M) (P25, P75) & $9.8(8.6,11.3)$ & $9.9(8.6,11.5)$ & -0.50 & 0.62 \\
\hline Height (cm, M) (P25, P75) & $75.4(70.0,82.0)$ & $76.0(70.0,84.0)$ & -1.50 & 0.13 \\
\hline Height-for-age $Z$ score & $-0.1(-0.8,0.6)$ & $0.1(-0.6,0.8)$ & -8.878 & $<0.001$ \\
\hline Weight-for-age $Z$ score & $0.0(-0.7,0.61)$ & $0.5(-0.5,0.6)$ & -0.39 & 0.70 \\
\hline \multicolumn{5}{|c|}{$\begin{array}{l}\text { Place of residence (urban, } 111 \text { [12.7]; } \\
\quad \text { rural, } 761 \text { [87.3]) }\end{array}$} \\
\hline Urban, $n(\%)$ & $1,625(29.6)$ & $3,856(70.4)$ & 12.39 & $<0.001$ \\
\hline Rural, $n(\%)$ & 488 (34.5) & $927(65.5)$ & - & - \\
\hline
\end{tabular}

and toddlers, 1,015 (14.7\%) children had vitamin D deficiency, and the prevalence of vitamin D deficiency in the $H$. pyloriseropositive group $(437 / 2113,20.7 \%)$ was significantly higher than that in the seronegative group $(676 / 4,783,12.1 \%)(P<$ $0.001)$. Compared with the group without vitamin $D$ deficiency, the age of vitamin $\mathrm{D}$ deficiency group was younger, and there were higher prevalence rates of anemia and iron deficiency in vitamin $\mathrm{D}$ deficiency group $(P<0.001)$. In addition, the height and weight of the vitamin $D$ deficiency group were lower than those of the vitamin D sufficiency group. After elimination of confounding effects of age and gender, WAZ and HAZ in vitamin $D$ deficiency group were all lower than those in

TABLE 2

Factors associated with vitamin D deficiency

\begin{tabular}{|c|c|c|c|}
\hline \multirow[b]{2}{*}{ Independent variable } & \multicolumn{2}{|c|}{ Groups } & \multirow[b]{2}{*}{$P$} \\
\hline & $\begin{array}{c}\text { Vitamin D deficiency } \\
n=1,015(14.7 \%)\end{array}$ & $\begin{array}{l}\text { Vitamin D sufficiency } \\
n=5,881(85.3 \%)\end{array}$ & \\
\hline Age (months) & & & $<0.001$ \\
\hline $6 \sim, n(\%)$ & $675(24.4)$ & $2091(75.6)$ & \\
\hline $12 \sim, n(\%)$ & $235(8.4)$ & $2577(91.6)$ & \\
\hline $24 \sim 36, n(\%)$ & $105(8.0)$ & $1,213(92.0)$ & \\
\hline Gender, $n(\%)$ & & & 0.355 \\
\hline Male & $586(15.1)$ & 3,301 (84.9) & \\
\hline Female & 429 (14.3) & $2580(85.7)$ & \\
\hline Anemia $^{\star}, n(\%)$ & & & $<0.001$ \\
\hline Yes & 335 (22.3) & $1,170(77.7)$ & \\
\hline No & $680(12.5)$ & $4,771(87.5)$ & \\
\hline Zinc deficiency†, $n$ (\%) & & & 0.044 \\
\hline Yes & $80(18.1)$ & 363 (81.9) & \\
\hline No & $935(14.5)$ & $5,518(85.5)$ & \\
\hline Iron deficiency $\ddagger$, $n$ (\%) & & & $<0.001$ \\
\hline Yes & $181(18.5)$ & $798(81.5)$ & \\
\hline No & $834(14.2)$ & $5,038(85.8)$ & \\
\hline Magnesium deficiency§, $n(\%)$ & & & 0.228 \\
\hline Yes & $1(10.0)$ & $9(90.0)$ & \\
\hline No & $1,014(14.7)$ & $5,872(85.3)$ & \\
\hline H. pylori-Ab & & & $<0.001$ \\
\hline H. pylori-Ab (+) & $437(20.7)$ & $1,676(79.3)$ & \\
\hline H. pylori-Ab (-) & $578(12.1)$ & $4,205(87.9)$ & \\
\hline Weight $(\mathrm{kg})$ & $8.8(8.0,9.9)$ & $10.1(8.8,11.6)$ & $<0.001$ \\
\hline Height $(\mathrm{cm})$ & $70.0(67.3,79.0)$ & $77.0(71.0,85.0)$ & $<0.001$ \\
\hline Height-for-age $Z$ score & $0.1(-0.7 .0 .7)$ & $0.1(-0.6,0.8)$ & $<0.001$ \\
\hline Weight-for-age $Z$ score & $0.2(-0.4 .0 .9)$ & $0.5(-0.2,1.1)$ & $<0.001$ \\
\hline $\begin{array}{l}\text { Place of residence (urban, } 111 \text { [12.7]; } \\
\quad \text { rural } 761 \text { [87.3]) }\end{array}$ & & & $<0.001$ \\
\hline Urban, $n(\%)$ & $861(15.7)$ & $4,620(84.3)$ & \\
\hline Rural, $n(\%)$ & 154 (10.9) & $1,261(89.1)$ & \\
\hline
\end{tabular}

* Anemia was defined according to Geneva, Switzerland 2011 guideline ${ }^{15}$

$\dagger \ddagger \S$ Zinc deficiency, iron deficiency, and magnesium deficiency were defined according to product specifications of corresponding kit. 
vitamin D sufficiency group $(P<0.001)$. The prevalence rates of vitamin $D$ deficiency and vitamin $D$ sufficiency in urban and rural subjects were $15.7 \%(861 / 5,481)$ and $10.9 \%(154 / 1,415)$, respectively $(P<0.001)$.

Multivariate logistic regression analysis of vitamin D deficiency. A multivariate logistic regression analysis was performed to identify the relevant factors for vitamin $D$ deficiency. Before the multivariate logistic regression analysis, the collinearity of covariate was checked, and the result illustrated that variables in our study were not highly collinear in the same model (Table 3). After correcting the confounding factors (age, anemia, zinc deficiency, WAZ, HAZ, and place of residence), the results suggested that the children with anemia were 1.62 times $(95 \% \mathrm{Cl}: 1.36,1.96)$ more likely to lack vitamin D compared with children without anemia. In addition, WAZ and the resident of rural area had significant associations with vitamin $\mathrm{D}$ deficiency Children with $\mathrm{H}$. pylori-positive antibody were 2.06 times $(95 \% \mathrm{Cl}: 1.77,2.38)$ more likely to be deficient in vitamin $\mathrm{D}$ compared with children who had $H$. pylorinegative antibody $(P<0.001$, Table 4$)$.

\section{DISCUSSION}

In 1994, the International Agency for Research on Cancer classified $H$. pylori as a class I carcinogen, ${ }^{16}$ and approximately 4.4 billion individuals suffer from $H$. pylori infection worldwide. $^{17}$ In China, the $H$. pylori infection prevalence is about 60-70\%. ${ }^{17-19}$ Helicobacter pylori infection-related diseases have been studied in some reports recently; therefore, there is no doubt that to carry out research on $H$. pylori infection has become a hot topic. In this study, we first evaluated the relationship between $H$. pylori infection and vitamin $D$ deficiency in apparently healthy infants and toddlers.

It is commonly stated that $H$. pylori infection chiefly occurs in childhood, and in our country, the prevalence of $H$. pylori infection in children seems to be in the range of $40-50 \% .^{17,20}$ There are several studies that provide us new viewpoints about $H$. pylori infection of children. First, recent studies have reported that most children acquiring $H$. pylori infections are before the age of 5 years. ${ }^{21}$ So it is reasonable to believe that $H$. pylori testing should be strengthened among children younger than 5 years. Serologic detection for $H$. pylori is a frequently used method for detecting the amount of $H$. pylori in children, whose sensitivity to $H$. pylori is more than $90 \%$ compared with histopathology-based studies. ${ }^{22}$ Helicobacter pylori antibody (H. pylori-Ab) detection can reflect a persistent or transient infection, which is considered as the most suitable method for the physical examination of healthy children because the specimens are easily available and results are not

TABLE 3

Collinearity diagnostics in multivariate logistic regression analysis of vitamin $\mathrm{D}$ deficiency

\begin{tabular}{lcc}
\hline \multicolumn{1}{c}{ Independent variable } & Tolerance & VIF \\
\hline Age & 0.93 & 1.07 \\
Male & 0.99 & 1.01 \\
anemia & 0.79 & 1.25 \\
Zinc deficiency & 0.98 & 1.01 \\
Iron deficiency & 0.80 & 1.25 \\
Urban rural 761 (87.3) & 0.95 & 1.05 \\
Weight-for-age Z score & 0.52 & 1.91 \\
Height-for-age Z score & 0.53 & 1.90 \\
\hline VIF = variance inflation factor. & &
\end{tabular}


Growth is an important but complicated issue; hence, the association between growth and $H$. pylori infection needs further study.

Nurinnisa finds out that the serum concentration of zine is dramatically higher in children with $\mathrm{H}$. pylori infection, but the elements of copper and magnesium have no differences between infected and noninfected children, ${ }^{31}$ and Anla reports that there are no significant differences in contents of calcium, magnesium, iron, zinc, selenium, and copper between the two groups. ${ }^{32}$ Besides, iron deficiency anemia is revealed to be associated with $H$. pylori infection. ${ }^{33,34}$ In our study, we unveiled that the contents of copper, iron, and magnesium in the $H$. pylori-seropositive group were higher than those in the $H$. pylori-seronegative group. These results were different from the data obtained from other reports, and we failed to find a significant relationship of anemia with $H$. pylori. Regarding to this finding, it may be due to the reason that we did not control the confounding effect of age, which had a huge effect on anemia and micronutrients. Therefore, we could not determine the correlation of the deficiency of trace elements or anemia with $H$. pylori infection.

The active form of vitamin $D$ in the human body is 1,25 $(\mathrm{OH})_{2} \mathrm{D} 3$, which maintains the calcium absorption and metabolism balance in the body. Vitamin D is also distinctly associated with the health of the immune and cardiovascular systems; thus, 1, $25(\mathrm{OH})_{2} \mathrm{D} 3$ is highly valued by families and communities for the health examinations of children. First, in our study, vitamin $D$ deficiency was detected in 1,015 cases (14.7\%); the prevalence of vitamin D deficiency in $H$. pyloriseropositive group was relatively higher than that in $H$. pylori-seronegative group (20.7\% versus $12.1 \%)$, hinting that vitamin $D$ deficiency was highly prevalent in these apparently healthy children with $H$. pylori infection. In addition, we found anemia was more common in vitamin $D$ deficiency group, and our logistic regression analysis revealed a significant association between vitamin $\mathrm{D}$ deficiency and anemia, consistent with the similar findings in other reports. ${ }^{35-37}$ Therefore, we emphasized the importance of correcting vitamin $D$ deficiency in anemic children. And last, after controlling for age, gender, and other possible confounders, we uncovered that WAZ was lower in vitamin D deficiency group than that in vitamin D sufficiency group, as another study concluded. ${ }^{38}$ However, the role of vitamin $D$ deficiency in underweight was in need of further study because of the complexity of growth.

The logistic regression analysis was used to make a further investigation about the relationship between $H$. pylori infection and vitamin $D$ deficiency in this study, and the result suggested that children with $H$. pylori-positive antibody were 2.06 times more likely to be vitamin $\mathrm{D}$ deficient compared with children who had negative $H$. pylori antibody (OR: 2.06; 95\% $\mathrm{Cl}: 1.77,2.38)$ after elimination for confounding factors. Recently, a research about the relationship of $25-\mathrm{OH}-\mathrm{D}$ with $H$. pylori infection has been published, which demonstrates that serum vitamin $D$ levels are significantly lower in the $H$. pylori-infected adults. ${ }^{14}$ Our finding also supported this result in children aged 6-36 months, but the causality of vitamin $\mathrm{D}$ deficiency and $H$. pylori infection could not be ascertained here because of the limitations of this research. Nevertheless, most researchers believe that vitamin $D$ deficiency is associated with an increased risk of $H$. pylori infection. Evidence from the clinical study of Oguzhan et al. suggests that vitamin $D$ deficiency may increase the failure rate of $H$. pylori radical treatment, ${ }^{39}$ and Kawarau et al. demonstrate the supplementation of $1,25(\mathrm{OH})_{2} \mathrm{D} 3$ decreases the rate of $H$. pylori infection in healthy elderly women aged 77-99 years. ${ }^{40}$ Some basic research works have tried to find out how vitamin D deficiency causes $H$. pylori infection. Guo et al. ${ }^{41}$ study the relationship between $H$. pylori infection and vitamin $D$ receptors and reveal that vitamin $D$ receptor mRNA expression significantly increases in $\mathrm{H}$. pylori-infected patients and vitamin $\mathrm{D}$ receptor is in positive correlation with chronic inflammation scores. These data give us more information about the anti-inflammatory mechanism of vitamin D; however, a recent research reported by $\mathrm{Hu}$ et al. ${ }^{42}$ indicates that the antimicrobial effect is mediated through the PDIA3 receptor but not vitamin D receptor. In all, this study still needs a further research.

\section{LIMITATIONS}

Our study had some limitations, and some of them had been mentioned earlier. Next, we would make a specific description of the limitations of this article as follows. First of all, our study was a cross-sectional study, the causality of vitamin $\mathrm{D}$ deficiency and $H$. pylori infection could not be identified. Second, the detection of $H$. pylori-Ab was qualitative, rather than quantitative, so we were unable to complete the further study of the dose-response relationship between $H$. pylori infection and 25-OH-D. Last, our study data were from a children's health center, and the month of the 25-OH-D assay was not available. Thus, confounding biases were unavoidable.

\section{CONCLUSION}

In China, $H$. pylori infection in the term of infancy and toddlerhood was still very common. Helicobacter pylori seropositivity was more commonly observed in infants and toddlers with vitamin $\mathrm{D}$ deficiency. The result suggested that there was a significant association between $H$. pylori seropositivity and vitamin $D$ deficiency in children aged 636 months. In addition, although weight, height, and anemia were not the main indicators of our study, the following results were also worth noting: 1) the HAZ of growth parameter was lower in $H$. pylori-seropositive group and 2) vitamin $D$ deficiency was associated with anemia and lower WAZ. We believed that this study would be helpful to the treatment and monitoring of vitamin D deficiency and $H$. pylori infection.

Received July 13, 2019. Accepted for publication December 5, 2019. Published online January 13, 2020.

Authors' addresses: Ting Gao, Department of Pediatrics, Central South University Third Xiangya Hospital, Changsha, China, and Department of Neurology, The affiliated Children's Hospital of Xi'an Jiaotong University, Xi'an Shaanxi, China, E-mail: tgao2019@163. com. Mengwen Zhao, Chen Zhang, Peipei Wang, Wenjuan Zhou, Shan Tan, and Lingling Zhao, Department of Pediatrics, Central South University Third Xiangya Hospital, Changsha, China, E-mails: zhaomengwen2011@163.com, 522704577@qq.com, peipei2011@163. com, wenjuan2011@163.com, tanshan2011@163.com, and Ilzhao2011@ 163.com.

\section{REFERENCES}

1. Gulcan M, Ozen A, Karatepe HO, Gulcu D, Vitrinel A, 2010. Impact of $H$. pylori on growth: is the infection or mucosal disease related to growth impairment? Dig Dis Sci 55: 2878-2886. 
2. Todo K, 2016. Severe Helicobacter pylori gastritis-related thrombocytopenia and iron deficiency anemia in an adolescent female. Ann Hematol 95: 835-836.

3. Brito HS, Braga JA, Loggetto SR, Machado RS, Granato CF, Kawakami E, 2015. Helicobacter pylori infection \& immune thrombocytopenic purpura in children and adolescents: a randomized controlled trial. Platelets 26: 336-341.

4. Fouda EM, Kamel TB, Nabih ES, Abdelazem AA, 2018. Helicobacter pylori seropositivity protects against childhood asthma and inversely correlates to its clinical and functional severity. Allergol Immunopathol (Madr) 46: 76-81.

5. Taye B, Enquselassie F, Tsegaye A, Amberbir A, Medhin G, Fogarty A, Robinson K, Davey G, 2017. Association between infection with Helicobacter pylori and atopy in young Ethiopian children: a longitudinal study. Clin Exp Allergy 47: 1299-1308.

6. Karachaliou M et al., 2017. Helicobacter pylori seropositivity and childhood neurodevelopment, the Rhea birth cohort in crete, Greece. Paediatr Perinat Epidemiol 3: 374-384.

7. Choi JS, Ko KO, Lim JW, Cheon EJ, Lee GM, Yoon JM, 2016. The association between Helicobacter pylori infection and body weight among children. Pediatr Gastroenterol Hepatol Nutr 19: 110-115.

8. Ortiz-Princz D, Daoud G, Salgado-Sabel A, Cavazza ME, 2016. Helicobacter pylori infection in children: should it be carefully assessed? Eur Rev Med Pharmacol Sci 20: 1798-1813.

9. Brawner KM et al., 2017. Helicobacter pylori infection is associated with an altered gastric microbiota in children. Mucosal Immunol 10: 1169-1177.

10. Testerman TL, Morris J, 2014. Beyond the stomach: an updated view of Helicobacter pylori pathogenesis, diagnosis, and treatment. World J Gastroenterol 20: 12781-12808.

11. Gu H, 2017. Role of flagella in the pathogenesis of Helicobacter pylori. Curr Microbiol 74: 863-869.

12. Goodman KJ, Correa P, Mera R, Yepez MC, Cerón C, Campo C, Guerrero N, Sierra MS, Bravo LE, 2011. Effect of Helicobacter pylori infection on growth velocity of school-age andean children. Epidemiology 22: 118-126.

13. Zielinska-Duda H, Czerwionka-Szaflarska M, 2007. Influence of Helicobacter pylori infection on chosen parameters physical development of children and youth. Pol Merkur Lekarski 22: 269-274.

14. Han C et al., 2019. Influence of serum vitamin D level on Helicobacter pylori eradication: a multi-center, observational, prospective and cohort study. J Dig Dis 20: 421-426.

15. Grossman Z, Hadjipanayis A, Stiris T, Del Torso S, Mercier JC, Valiulis A, Shamir R, 2017. Vitamin D in European childrenstatement from the European Academy of Paediatrics (EAP). Eur J Pediatr 176: 829-831.

16. Talebi Bezmin AA, Lee YY, 2016. Chinese Helicobacter pylori vaccine: solution for an old challenge? World J Gastrointest Pharmacol Ther 7: 412-7415.

17. Hooi $\mathrm{J}$ et al., 2017. Global prevalence of Helicobacter pylori infection: systematic review and meta-analysis. Gastroenterology 155: 420-429.

18. Ford AC, Axon AT, 2010. Epidemiology of Helicobacter pylori infection and public health implications. Helicobacter Null 15: 1-6.

19. LiZet al., 2010. Epidemiology of peptic ulcer disease: endoscopic results of the systematic investigation of gastrointestinal disease in China. Am J Gastroenterol 105: 2570-2577.

20. Zabala TB, Lucero Y, Lagomarcino AJ, Orellana-Manzano A, George S, Torres JP, O'Ryan M, 2017. Review: prevalence and dynamics of Helicobacter pylori infection during childhood. Helicobacter 22: e12399.

21. Harris PR, Smythies LE, Smith PD, Perez-Perez GI, 2013. Role of childhood infection in the sequelae of $H$. pylori disease. Gut Microbes 4: 426-438.

22. Wang YK, Kuo FC, Liu CJ, Wu MC, Shih HY, Wang SSW, Wu JY, Kuo CH, Huang YK, Wu DC, 2015. Diagnosis of Helicobacter pylori infection: current options and developments. World $J$ Gastroenterol 21: 11221-11235.

23. Al-Hussaini A, Al Jurayyan A, Bashir S, Alshahrani D, 2019. Where are we today with Helicobacter pylori infection among healthy children in Saudi Arabia? Saudi J Gastroenterol 25: 309-318.
24. Hasosah M et al., 2015. Prevalence and risk factors of Helicobacter pylori infection in Saudi children: a three-year prospective controlled study. Helicobacter 20: 56-63.

25. Ding Z, Zhao S, Gong S, Li Z, Mao M, Xu X, Zhou L, 2015. Prevalence and risk factors of Helicobacter pylori infection in asymptomatic Chinese children: a prospective, cross-sectional, population-based study. Aliment Pharmacol Ther 42: 10191026.

26. Vilchis $\mathrm{J}$ et al., 2009. Association of Helicobacter pylori infection and height of Mexican children of low socioeconomic level attending boarding schools. Am J Trop Med Hyg 81: 1091-1096.

27. Süoglu OD, Gökçe S, Saglam AT, Sökücü S, Saner G, 2007. Association of Helicobacter pylori infection with gastroduodenal disease, epidemiologic factors and iron-deficiency anemia in Turkish children undergoing endoscopy, and impact on growth. Pediatr Int 49: 858-863.

28. Egorov Al, Sempértegui F, Estrella B, Egas J, Naumova EN, Griffiths JK, 2010. The effect of Helicobacter pylori infection on growth velocity in young children from poor urban communities in Ecuador. Int J Infect Dis 14: e788-e791.

29. Cherian S, Forbes D, Sanfilippo F, Cook A, Burgner D, 2009. Helicobacter pylori, helminth infections and growth: a crosssectional study in a high prevalence population. Acta Paediatr 98: 860-864.

30. Janjetic MA, Mantero P, Cueto RE, Balcarce N, Zerbetto de Palma G, Catalano M, Zubillaga MB, Boccio JR, Goldman CG, 2015. Dietary and anthropometric indicators of nutritional status in relation to Helicobacter pylori infection in a paediatric population. Br J Nutr 113: 1113-1119.

31. Ozturk N, Kurt N, Ozgeris FB, Baygutalp NK, Tosun MS, Bakan N, Bakan E, 2015. Serum zinc, copper, magnesium and selenium levels in children with Helicobacter pylori infection. Eurasian $J$ Med 47: 126-129.

32. Hu A et al., 2018. Serum concentrations of 15 elements among Helicobacter pylori-infected residents from Lujiang county with high gastric cancer risk in Eastern China. Biol Trace Elem Res 186: 21-30.

33. Bruel H, Dabadie A, Pouedras P, Gambert C, Le Gall E, Jezequel C, 1993. Helicobacter pylori gastritis manifested by acute anemia. Ann Pediatr (Paris). Ann Pediatr (Paris) 40: 364-367.

34. Gheibi S, Noroozi M, Hejaz S, Karamyyar M, Farrokh-Eslamlou $H, 2016$. Severe anemia and Helicobacter pylori infection in school age children; A case reports. Iran J Ped Hematol Oncol 6: 64-69.

35. Smith EM, Alvarez JA, Martin GS, Zughaier SM, Ziegler TR, Tangpricha $V, 2015$. Vitamin $D$ deficiency is associated with anaemia among African Americans in a US cohort. Br J Nutr 113: $1732-1740$.

36. Nikooyeh B, Neyestani TR, 2018. Poor vitamin D status increases the risk of anemia in school children: national food and nutrition surveillance. Nutrition 47: 69-74.

37. Smith EM, Tangpricha V, 2015. Vitamin D and anemia: insights into an emerging association. Curr Opin Endocrinol Diabetes Obes 22: 432-438.

38. Mokhtar RR, Holick MF, Sempertegui F, Griffiths JK, Estrella B, Moore LL, Fox MP, Hamer DH, 2018. Vitamin D status is associated with underweight and stunting in children aged 636 months residing in the Ecuadorian Andes. Public Health Nutr 21: 1974-1985.

39. Yildirim $O$, Yildirim $T$, Seckin $Y$, Osanmaz $P$, Bilgic $Y$, Mete $R$, 2017. The influence of vitamin $D$ deficiency on eradication rates of Helicobacter pylori. Adv Clin Exp Med 26: 1377-1381.

40. Kawaura A, Takeda N, 2006. Inhibitory effect of long term 1 a -hydroxy vitamin D3 administration on Helicobacter pylori infection. J Clin Biochem Nutr 38: 103-106.

41. Guo L, Chen W, Zhu H, Chen Y, Wan X, Yang N, Xu S, Yu C, Chen L, 2014. Helicobacter pylori induces increased expression of the vitamin d receptor in immune responses. Helicobacter 19: 37-47.

42. Hu W et al., 2019. Vitamin D3 activates the autolysosomal degradation function against Helicobacter pylori through the PDIA3 receptor in gastric epithelial cells. Autophagy 15: 707-725. 